\title{
The development of an anxiety assessment scale for pregnant women in labor
}

\author{
Gülgün Durat, PhD, Gümrah D. Çulhacik, MD, Özlem Doğu, PhD, Zekiye Turan, PhD, \\ Işı Atasoy, MD, Eylem Toker, PhD.
}

\begin{abstract}
الأهداف : تطو ير أداة قياس صالحة وموثوق بها للكشف الكف عن حالات

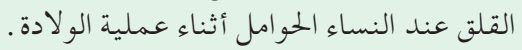

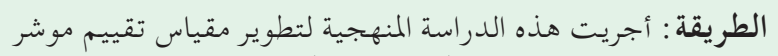

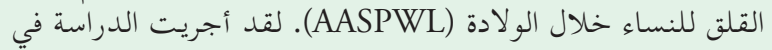

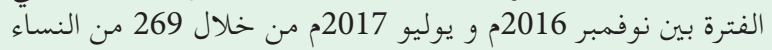

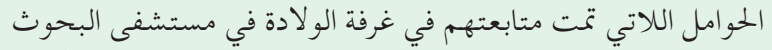

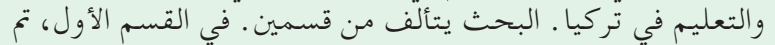

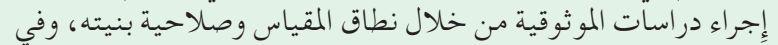

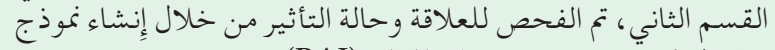

بواسطة أستخدام مقياس بيك للقلق (BAI) .

النتائج: صلاحية البنية؛ تم فحصها من خلال استخدام تقنيات

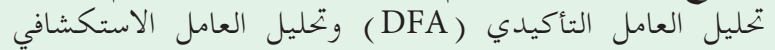

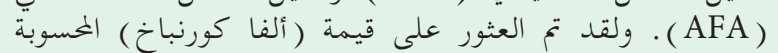

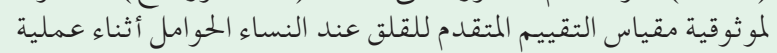

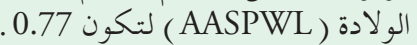

الخاتمة: نتيجة للتحاليل الإحصائية المعمولة، تبين بأن AASPWL

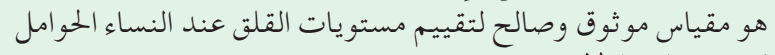

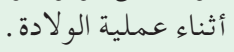

Objectives: To develop a valid and reliable measurement tool to determine the anxiety level of pregnant women in labor.

Methods: This study is a methodological research for developing an Anxiety Assessment Scale for Pregnant Women in Labor (AASPWL) and descriptive research for determining the anxiety level of pregnant women in labor. This study included a total of 269 pregnant women from the delivery room of a training and research hospital between November 2016 and July 2017. The study consists of 2 stages: the first stage includes scale content, construct validity, and reliability; the second stage involves examination of the relationship and effects by establishing a model with the Beck Anxiety Inventory (BAI).
Results: Construct validity was established using a confirmatory factor analysis (CFA) and an exploratory factor analysis (EFA). Cronbach's alpha value was calculated to be 0.77 for the reliability of the developed AASPWL.

Conclusion: The AASPWL is a reliable and valid scale that can be used to assess the anxiety level of women in labor.

Saudi Med J 2018; Vol. 39 (6): 609-614 doi: 10.15537/smj.2018.6.22266

From the Faculty of Health Science (Durat, Çulhacik, Doğu, Turan, Atasoy), Sakarya University, Sakarya and from the Kahramanmaras School of Health (Toker), Kahramanmaraş Sütçü İmam University, Kahramanmaras, Turkey.

Received 22nd February 2018. Accepted 9th May 2018.

Address correspondence and reprint request to: Dr. Gülgün Durat, Faculty of Health Science, Sakarya University, Sakarya, Turkey. E-mail: gdurat@sakarya.edu.tr

ORCID ID: orcid.org/0000-0002-9889-3622

$\mathrm{P}$ regnancy is one of the most important events of a woman's life, in which biological and psychosocial changes are experienced simultaneously. Studies show that the positive feelings experienced in this period are accompanied by negative feelings such as concern, stress, and fear and that the health of both the mother and the baby declines and psychiatric disorders emerge. ${ }^{1-3}$ According to the literature, the fear and anxiety mainly originate from the delivery due to factors such as labor pain, obstetric damage, emergency cesarian section, possible complications, death, inability to perform motherhood tasks, concern of survival during labor, concern for the baby's health, lack of trust in the health personnel, and more. ${ }^{4-6} \mathrm{~A}$ study conducted by Adams et $\mathrm{al}^{7}$ on 2206 women who had planned vaginal deliveries reported that interventional procedures (epidural analgesia, labor induction, labor augmentation) were 
necessary in $17 \%$ of women who feared childbirth and $10.9 \%$ of these took place compulsorily with a cesarean section. Midwives, who play an active role in the management of delivery, must handle the anxiety and fear related with childbirth while providing observation and care for the pregnant woman in labor. Effective care during this process constitutes the basis of midwifery in the intrapartum period. However, assessment of fear and anxiety may be overlooked during labor. ${ }^{8-10}$ In line with this information, the anxiety of pregnant women must be determined especially in the labor period due to the fear, anxiety, and secondary problems experienced during delivery. Although there are scales developed to determine the anxiety during the pregnancy and postpartum periods, scales such as State-Trait Anxiety Inventory (STAI), Visual Analogue Scale (VAS), Impact of Event Scale (IES) and Wijma-Delivery ExpectancyExperience Scale (W-DEQ) are generally used for measuring anxiety at the time of delivery. ${ }^{11-16}$ However, none specific questions to measure anxiety during delivery were included. Therefore, the objective of this study was to develop a valid and reliable measurement tool that will facilitate determining anxiety levels of pregnant women coming to the hospital for childbirth at an early period during labor and to contribute to ensuring provision of necessary midwifery care.

Methods. This study involves methodological research for developing an Anxiety Assessment Scale for Pregnant Women in Labor (AASPWL) and descriptive research for determining the anxiety level of pregnant women in labor.

The study was conducted in 2 sections. The first section examines the scope, validity, and reliability of the scale while the second section investigates the relationship with the previously used Beck Anxiety Scale. ${ }^{17}$

Section 1. Scale development. Drafting of the items and expert's opinion. A question pool of 17 items was prepared with special attention paid to ensuring that the scale questions were clear, comprehensible, and relevant to the subject. Expert's opinions were obtained to determine whether the items of the measurement instrument were suitable for the measurement

Disclosure. Authors have no conflict of interests, and the work was not supported or funded by any drug company. This study is supported by the Sakarya University Rectorate, Scientific Research Projects Commission (BAP No: 2016-11-01-002), Sakarya, Turkey. objective and whether they were representative of the area intended to be measured. The scale form was presented to 19 experts for evaluation (10 from the Gynecology and Obstetrics Nursing Department, 7 from the Psychiatry Nursing Department, one expert in the Turkish Language, and one expert in Statistics). In line with the opinions of the experts, the scale form was finalized to 9 items, which were scored from 1-5. Reverse (symmetrical) coding was applied to the positive questions so as to ensure similar scoring and interpretation of each item. Total score of the AASPWL was calculated by dividing the scores from the answers given to the 9 items of the scale into the number of questions. A high mean score for the scale and subdimension (5-point scale: highest $=5$ points, lowest $=$ one point) indicates that the anxiety of pregnant women in labor is affected negatively.

Written informed consent was obtained from the management of the related institution of the study sample and Research Ethics Committee's Approval was obtained from the Sakarya Faculty of Medicine, prior to study commencement. The objective and period of the study were explained to the pregnant women along with the expectations of them, and their informed consent was obtained on a voluntary basis. Actions were taken in line with the rules set forth in the Helsinki Declaration during the data collection stage.

Application of the scale. The population of this study was consisted by pregnant women $(n=2000)$ enrolled at a Public Hospital in Sakarya, Turkey between November 2016 and July 2017. Individuals with a high-risk pregnancy, chronic illness, psychiatric problems, and communication issues were not included in the study. The number of pregnant women enrolled in the study sample was 269 using the simple random sampling formula. The scale was applied during admission to the labor room before any intervention was required. A draft of the scale was applied to 20 individuals in a pilot study and then evaluated for comprehensibility and amended to include any necessary revisions.

Validity and reliability analysis of the scale. The expert's opinions and a factor analysis were applied to determine the validity. A test-retest analysis and Cronbach's alpha analysis were applied to establish reliability. Examination of the factors' structures included a confirmatory factor analysis (CFA) with 119 people and an exploratory factor analysis (EFA) with 150 people. The test-retest method was not applied as the scale was developed to assess the anxiety of pregnant women during delivery.

Section 2 - Relationship analysis for the AASPWL and BAI scales. Correlation analyses were performed 
following establishment of a model to determine the relationship effects between the AASPWL that is developed and the BAI that was used previously.

Data analysis. Data was transferred to the IBM SPSS Statistics 23 and IBM SPSS AMOS 23 (Armonk, NY, USA) programs. In an evaluation of the study data, the distribution of the sample mean approached normal distribution for $n \rightarrow \infty$ in numeric variables according to the Law of Large Numbers. ${ }^{18}$ Descriptive statistics (number and percentage) were provided for the categorical variables. Expert's opinions were evaluated with the Kendall's W test. Statistically, values $p<0.05$ were considered to be significant.

Results. Examination of the AASPWL subdimensions and the mean total points revealed that anxiety is at a high level for pregnant women in labor (3.54 \pm 3.56$)$. The highest anxiety score was found in the motherhood constellation sub-dimension $(4.11 \pm 4.33)$ (Table 1).

Section 1 - AASPWL development analysis. Content validity. Eight items with an index below 0.80 were deleted in line with the opinions of the 19 experts (decreased to nine items), and no further problems in the scale's content were observed. The Kendall's W concordance test revealed no significant differences between the opinions of the experts (W=0.090; $p=0.080$ ). The final scale consisted of 2 sub-dimensions and a total of 9 items, of which 6 are in the birth process sub-dimension and 3 were in motherhood constellation sub-dimension and was found to be statistically valid and reliable.
Scale validity. Exploratory factor analysis and CFA were used to determine the construct validity of the scale. The Kaiser-Meyer-Olkin (KMO) and Bartlett's sphericity tests were used to test the suitability of the data to the sampling group and adequacy of the sampling prior to the construct validity analyses. The $\mathrm{KMO}$ coefficient over 0.60 and the significant output of the Bartlett test indicate that the data was suitable for further factor analysis. ${ }^{19}$ In this study, the KMO value was found to be 0.781 ; thus, the factor analysis results to be applied to the data were useful and useable.

Table 2 - Scale factor loads ( $\mathrm{n}=150)$.

\begin{tabular}{lccc}
\hline Variables & Factor loads & Variance \% & Eigen value \\
\hline AASPWL & & & \\
Birth process & & 35.096 & 3.159 \\
Question 2 & 0.759 & & \\
Question 7 & 0.746 & & \\
Question 6 & 0.743 & & \\
Question 13 & 0.727 & & \\
Question 1 & 0.680 & & \\
Question 14 & 0.673 & & \\
Motherhood constellation & & 18.821 & \\
Question 11 & 0.824 & \\
Question 8 & 0.702 & \\
$\quad$ Question 3 & 0.638 & \\
Total percentage of variance \\
explained
\end{tabular}

Table 1 - Descriptive data for the scale questions $(n=269)$.

\begin{tabular}{|c|c|c|c|c|}
\hline Questions of the AASPWL & Min & Max & Mean & SD \\
\hline \multicolumn{5}{|l|}{ Birth process } \\
\hline I am afraid of being along during delivery & 1 & 5 & 3.07 & 1.477 \\
\hline I am currently exhausted/tired. & 1 & 5 & 3.41 & 1.362 \\
\hline I am afraid that my baby may be harmed during delivery & 1 & 5 & 3.74 & 1.344 \\
\hline I feel weak. & 1 & 5 & 3.02 & 1.367 \\
\hline I am concerned that I may be harmed during delivery & 1 & 5 & 3.08 & 1.414 \\
\hline I feel like crying/I can cry at any time. & 1 & 5 & 3.20 & 1.506 \\
\hline \multicolumn{5}{|l|}{ Motherhood constellation } \\
\hline I think of my baby and become very happy & 1 & 5 & 1.58 & 0.961 \\
\hline $\begin{array}{l}\text { When I have labor pain, I think that delivery is approaching and I feel } \\
\text { good. }\end{array}$ & 1 & 5 & 2.50 & 1.271 \\
\hline Birth process is worth it because I will be holding my baby in my arms & 1 & 5 & 1.60 & 1.023 \\
\hline \multicolumn{5}{|l|}{ Mean } \\
\hline Motherhood Constellation Sub-dimension & 1 & 5 & 4.11 & 4.33 \\
\hline Birth Process Sub-dimension & 1 & 5 & 3.26 & 3.33 \\
\hline AASPWL & 1 & 5 & 3.54 & 3.56 \\
\hline
\end{tabular}




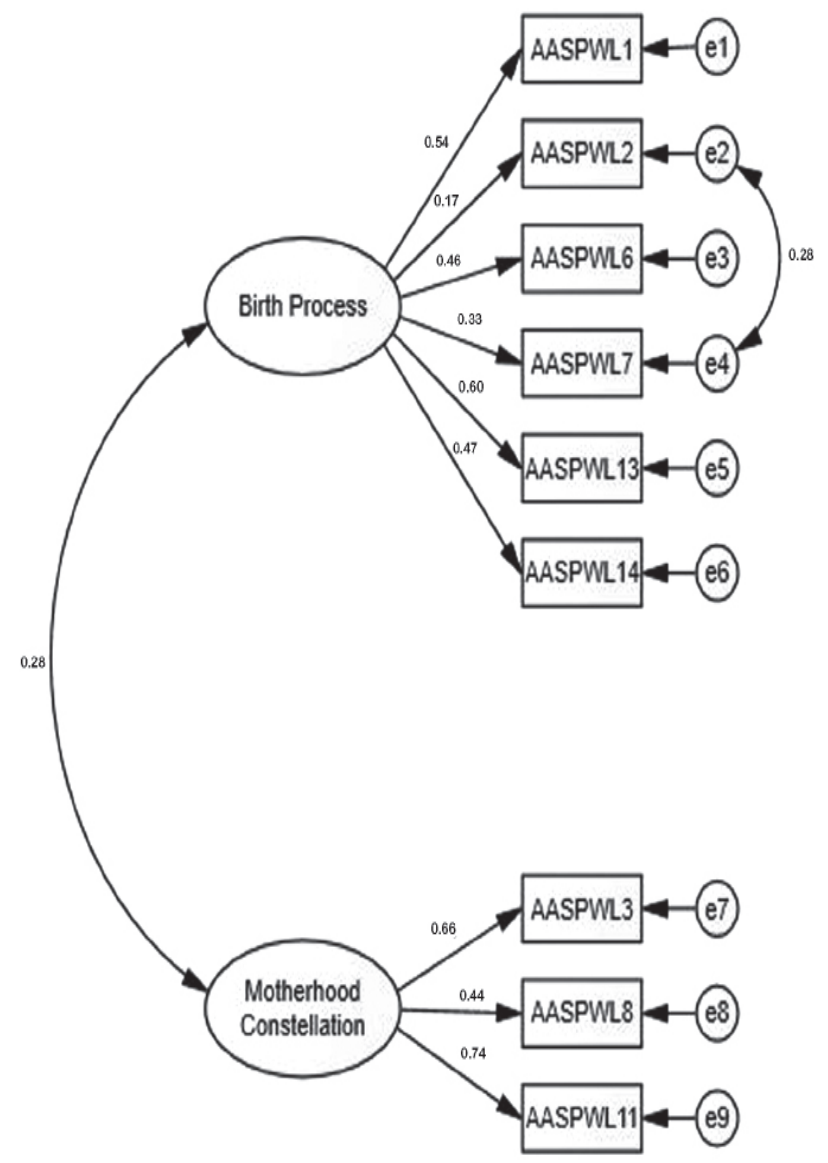

Figure 1 - First order confirmatory factor analysis modeling with 2 sub-dimensions. AASPWL - Anxiety Assessment Scale for Pregnant Women in Labor

The Bartlett's sphericity test indicated significantly high relationships between the variables and that the data was suitable for the factor analysis $\left(x^{2}: 353,813\right.$, SD: 36 , $p=0.000$ ).

Confirmatory factor analysis was used to assess information on the quality of the main factors determined by EFA, general structure of the scale, and the level at which the scale explained anxiety during labor.

Exploratory factor analysis (EFA). Exploratory factor analysis was applied to this data set to determine the construct validity of the scale and establish the dimensioning factor loads of the items included in the scale, and "Principal Components Method" was the preferred factor extraction method. No limitations were imposed on factor number. Statements with factor loads over 0.50 were included. While the birth process sub-dimension explained $35.1 \%$ of the total AASPWL
Table 3 - Standard regression coefficients of 119 participants.

\begin{tabular}{lcc}
\hline Questions & $\begin{array}{c}\text { AASPWL } \\
\text { Sub-dimensions }\end{array}$ & $\begin{array}{c}\text { Standard Regression } \\
\text { Coefficients }\end{array}$ \\
\hline Question 1 & Birth process & $0.543^{* *}$ \\
Question 2 & Birth process & $0.169^{*}$ \\
Question 6 & Birth process & $0.459^{* *}$ \\
Question 7 & Birth process & $0.326^{* *}$ \\
Question 13 & Birth process & $0.600^{* *}$ \\
Question 14 & Birth process & $0.466^{* *}$ \\
Question 3 & Motherhood constellation & $0.660^{* *}$ \\
Question 8 & Motherhood constellation & $0.439^{* *}$ \\
Question 11 & Motherhood constellation & $0.736^{* *}$ \\
\hline
\end{tabular}

variance, the motherhood constellation sub-dimension explained $18.8 \%$. Together, these 2 sub-dimensions explained $53.9 \%$ of the total variance $(n=150)$. The cut-off point was 0.50 in the scale analysis and all items remained over 0.50 . Overall, the factor loads of the 9 items were found to vary between 0.63 and 0.83 (Table 2).

Confirmatory factor analysis. In the first stage, a first degree CFA model was created, in which 2 factordimensions were included as latent variables and the statements forming these factors were included as indicator variables $(n=119)$ (Figure 1). The maximum likelihood method, which is frequently used in structural equation modeling and gives reliable results even in conditions without normal distribution, was used in the second phase of model estimation. The aim was to estimate the errors of the observable variables, variances of the latent variables, and parameters covering the regression coefficients related to the paths drawn from the observable variables to the latent variables.

Fit indexes for the first order CFA model with 2 sub-dimensions were examined in the final stage. Examination of the findings in Table 3 revealed that the structure of 2 factors of the scale has a good fit. Moreover, there was a positive but small relationship $(\mathrm{r}=0.26)$ between the sub-dimensions. Examination of the fit values revealed that the Chi square/degree of freedom ( $x^{2} / \mathrm{df}$ : 1.737), root mean square error of approximation (RMSEA: 0.079), and standardized root mean square residue (SRMR: 0.080) values were acceptable; while the incremental fit index (IFI: 0.860), Tucker-Lewis index (TLI: 0.780), and comparative fit index (CFI: 0.847) values were unacceptable. ${ }^{20-22}$ In general, the AASPWL was found to be acceptable upon evaluation of the fit indexes. 
Table 4 - Examination of the relationship between Anxiety Assessment Scale for Pregnant Women in Labor and the Beck Anxiety Scale ( $\mathrm{n}=269)$.

\begin{tabular}{|c|c|c|c|c|c|c|}
\hline $\begin{array}{l}\text { Scales and sub- } \\
\text { dimensions }\end{array}$ & $\begin{array}{c}\text { Subjective } \\
\text { anxiety }\end{array}$ & $\begin{array}{c}\text { Somatic } \\
\text { symptoms }\end{array}$ & Beck total & $\begin{array}{l}\text { Motherhood } \\
\text { Constellation }\end{array}$ & Birth process & TAS \\
\hline Subjective anxiety & 1 & 0.674 & 0.948 & 0.466 & -0.076 & 0.373 \\
\hline $\mathrm{r}$ & & $0.000^{\ddagger}$ & $0.000^{\ddagger}$ & $0.000^{\ddagger}$ & 0.217 & $0.000^{\ddagger}$ \\
\hline \multicolumn{7}{|l|}{$\mathrm{p}$} \\
\hline Somatic symptoms & & 1 & 0.874 & 0.311 & 0.052 & 0.287 \\
\hline $\mathrm{r}$ & & & $0.000^{\ddagger}$ & $0.000^{\ddagger}$ & 0.395 & $0.000^{\ddagger}$ \\
\hline \multicolumn{7}{|l|}{$\mathrm{p}$} \\
\hline Beck total & & & 1 & 0.440 & -0.027 & 0.369 \\
\hline $\mathrm{r}$ & & & & $0.000^{\ddagger}$ & 0.657 & $0.000^{\ddagger}$ \\
\hline \multicolumn{7}{|l|}{$\mathrm{p}$} \\
\hline \multicolumn{6}{|l|}{ constellation } & 0.929 \\
\hline $\mathrm{r}$ & & & & & $0.003^{\dagger}$ & $0.000^{\ddagger}$ \\
\hline \multicolumn{7}{|l|}{$\mathrm{p}$} \\
\hline \multicolumn{7}{|l|}{ Birth process } \\
\hline $\mathrm{r}$ & & & & & 1 & 0.530 \\
\hline $\mathrm{p}$ & & & & & & $0.000^{\ddagger}$ \\
\hline TAS & & & & & & 1 \\
\hline \multicolumn{7}{|l|}{$\mathrm{r}$} \\
\hline $\mathrm{p}$ & & & & & & \\
\hline
\end{tabular}

Scale reliability. Internal consistency analysis was performed and Cronbach's alpha value calculated for the reliability of the developed AASPWL was found to be 0.77 . Moreover, the values remained between 0.73 and 0.78 when Cronbach's alpha values were examined individually when each item in the scale was removed. These results indicate consistency between the items constituting the developed scale, the characteristic intended to be measured, and that there is a high level of connection between all scale items in terms of consistency.

Section 2. Relationship analysis for the AASPWL and BAI scales. The relationship between the developed scale and the BAI, previously used to measure anxiety during labor, was examined. Cronbach's alpha value for the BAI was calculated as 88.9. An acceptable Cronbach's alpha value higher than 0.70 was found for the AASPWL and BAI. ${ }^{23}$ The Pearson correlation analysis revealed a moderate level $(36.9 \%)$ of a statistically significant positive relationship was found between the AASPWL and BAI $(p<0.05)$.

Discussion. In this study, we developed a 9-item AASPWL with 2 conceptual sub-dimensions to measure anxiety during labor. The first sub-dimension covered anxiety related to the birth process, called "birth process" and the second covered anxiety related to motherhood, called "motherhood constellation."
"Motherhood constellation" is a term from the literature coined by Daniel Stern that refers to the new and unique arrangement of a woman's mental structure after the birth of her baby. It covers the concern of the mother related to the survival and growth of her baby, safe bonding between the mother and the baby, characteristics of a supportive environment, and rearrangement of the mother's character starting with pregnancy. ${ }^{24}$ The application of the AASPWL in this study revealed high anxiety among expectant mothers in the general mean score. This broke down into high anxiety levels from the motherhood constellation subdimension and medium anxiety levels from the birth process sub-dimension (Table 1).

The correlation analysis applied between the AASPWL and the BAI found a statistically significant moderate relationship $(\mathrm{r}=0.369)$. In the literature, Beck et $\mathrm{al}^{17}$ reported a relationship of $\mathrm{r}=0.51$ between the BAI and the Hamilton Anxiety Scale. A significant relationship is found between BAI and STAI TX-1 (State) at a rate of $r=0.61$ and between BAI and STAI TX-2 (Trait) at a rate of $\mathrm{r}=0.59(p<0.001)$ in a study by Avci. ${ }^{25}$ A very strong relationship was also observed between BAI and State-Trait Anxiety Inventory (STAI) $(\mathrm{r}=0.47-0.58) .{ }^{12}$ The relationship in our study is slightly lower than those from the literature, likely due to the BAI's focus on somatic symptoms while the AASPWL is designed for pregnant women in labor. However, the 
absence of a negative relationship between the developed AASPWL and BAI and the presence of a statistically significant positive and moderate relationship, confirm that our scale successfully measures anxiety.

In conclusion, the AASPWL developed in this study aptly assess the anxiety of pregnant women in labor. The statistical analyses establish that the AASPWL is a useful tool for determining anxiety levels in scientific research and a reliable and valid scale for assessing anxiety levels of women in labor. Although there are many scales that assess anxiety, stress, and depression, there are no specific scales for pregnant women in labor. Furthermore, the labor phase is a difficult and painful process for women. Thus, conciseness of the AASPWL (9 items) represents an advantage for this particular application (pregnant women in labor). Moreover, the scale is well suited to contribute to the literature in terms of mother-infant health and well-being because it contains questions specific to both the mother and the infant that may be informative beyond the labor. Future studies include: examination of different studies in which the AASPWL is used, translation of the AASPWL into different languages, and application to pregnant women in labor in different cultures to assess its effectiveness.

There are a few limitations to this study. The main limitation of this study is that only primipar pregnants who have spontaneous vaginal deliveries are included. The study was conducted in Sakarya in Turkey. Thus, these results may not reflect the whole country.

Acknowledgment. We would like to thank Assist. Prof. Dr. Mehtap Sönmez for her contributions and American Manuscript Editors for English language editing.

\section{References}

1. Türen E. Maternal oxytocin, cortisol and prolactin levels effect in the prenatal mother-infant bonding and the relationship between mother's depression, anxiety, stress level. Konya (TR): Necmettin Erbakan University, Faculty of Meram Medicine, Department of Obstetrics and Gynecology; 2014

2. Vırıt 0, Akbaş E, Savaş HA, Sertbaş G, Kandemir H. Association between the level of depression and anxiety with social support in pregnancy. Archives of Neuropsychiatry 2008; 45: 9-13.

3. Yiğit Günay E. Gebelerde kaygı düzeyi: "Cambridge Kaygı Ölçeği”nin geçerlik ve güvenirlik çalışması. İstanbul (TR): İstanbul University, In Health Science, Department of Midwifery; 2013.

4. Barber V, Linsell L, Locock L, Powell L, Shakeshaft C, Lean K, Colman J, Juszczak E, Brocklehurst P. Electronic fetal monitoring during labour and anxiety levels in women taking part in a RCT. British Journal of Midwifery 2013; 21: 394-403.

5. Floris L, Irion O. Association between anxiety and pain in the latent phase of labour upon admission to the maternity hospital: Aprospective, descriptive study. Journal of Health Psychology 2015; 20: 445-455.
6. Kitapçıŏlu G, Yanıkkerem E, Sevil Ü, Yüksel D. Fear of childbirth and the postpartum period: A scale development and Validation Study. Adnan Menderes Üniversitesi Tip Fakültesi Dergisi 2008; 9: 47-54.

7. Adams S, Eberhard-Gran M, Eskild A. Fear of childbirth and duration of labour; a study of 2206 women with intended vaginal delivery. An International Journal of Obstetrics and Gynaecology 2006; 10: 1111.

8. Abushaikha L, Sheil EP. Labor stress and nursing support: how do they relate? Journal of International Women's Studies 2006; 7: 198-209.

9. Körükçü HÖ. The study of reliability and validity of the Wijma Delivery Expectancy/Experience Questionnaire of the Version A. Antalya (TR): Akdeniz University, Institute of Health Science, Department of Obstetrics and Gynecology Nursing; 2009.

10. Tumblin A, Simkin P. Pregnant women's perceptions of their nurse's role during labor and delivery. Birth 2001; 28: 52-56.

11. Üst ZD, Pasinlioğlu T, Özkan H. Investigation of Anxiety Levels of Pregnant Women in Labor. Journal of Anatolia Nursing and Health Sciences 2013; 16: 110-115.

12. Julian LJ. Measures of anxiety: State-Trait Anxiety Inventory (STAI), Beck Anxiety Inventory and Depression Scale- Anxiety (HADS-A). Arthritis Care and Research 2011; 63: S467-S472.

13. Garthus-Niegel S, Storksen HT, Von Soest T, Eberhard-Gran M. The Wijma delivery expectancy/experience questionnaire: a factor analytic study. Journal of Psychosomatic Obstetrics \& Gynecology 2011; 32: 160-163.

14. Beck JG, Grant DM, Read JP, Clapp JD, Coffey SF, Miller LM, Palyo SA. The impact of event scale-revised: psychometric properties in a sample of motor vehicle accident survivors. Journal of Anxiety Disorder 2008; 22: 187-198.

15. Şahin N, Dinç H, Dişsiz M. Pregnant women's fear of childbirth and related factors. Zeynep Kamil Tip Bülteni 2009; 40: 57-62.

16. Chang MY, Wang SY, Chen CH. Effects of massage on pain and anxiety during labour: a randomized controlled trial in Taiwan. Journal of Advanced Nursing 2002; 38: 68-73.

17. Beck AT, Epstein N, Brown G, Steer RA. An inventory for measuring clinical anxiety: psychometric properties. Journal of Consulting and Clinical Psychology 1988; 56: 893-897.

18. İnal HC, Günay S. Probability and mathematical statistics. Ankara (TR): Hacettepe Üniversitesi Yayınları, 2002.

19. Büyüköztürk Ş. Faktör Analizi: Temel Kavramlar ve Ölçek Geliştirmede Kullanımı. Educational Administration: Theory and Practice 2002; 8: 470-483.

20. Meydan CH, Şeşen H. Structural equation modeling AMOS applications. Ankara (TR): Detay Yayıncilık; 2011.

21. Hu LT, Bentler PM. Cutoff criteria for fit indexes in covariance structural analysis: Conventional criteria versus new alternatives. Structural Equation Modeling: A Multidisciplinary Journal 1999; 6: 1-55.

22. Tabachnick BG, Fidel LS. Using Multivariate Statistics. 4th ed. Massachusetts (MA): Allyn \& Bacon, Inc; 2001.

23. Nunnally JC. Psychometric Theory. 2nd ed. New York (NY): McGrawHill; 1978.

24. Öztürk O, Uluşahin NA. Mental Health and Disorders. 14th ed. Ankara (TR): Nobel Tip Kitapevleri; 2016. p. 629.

25. Avc1 GM. The study of validity and reliability of Beck Anxiety Inventory. Izmir (TR): Ege University, Institute of Health Science, Department of Clinical Psychology; 1995. 